\title{
Ginsenoside Rg3 enhances the inhibitory effects of chemotherapy on esophageal squamous cell carcinoma in mice
}

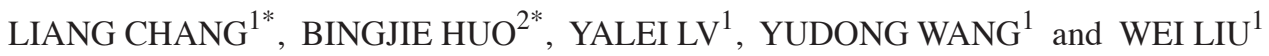 \\ Departments of ${ }^{1}$ Medical Oncology and ${ }^{2}$ Traditional Chinese Medicine, \\ The Fourth Hospital of Hebei Medical University, Shijiazhuang, Hebei 050011, P.R. China
}

Received June 25, 2014; Accepted July 1, 2014

DOI: $10.3892 / \mathrm{mco} .2014 .355$

\begin{abstract}
The present study was conducted in order to investigate the inhibitory effects of ginsenoside $\mathrm{Rg} 3$ combined with chemotherapy on Eca-109 esophageal squamous cell carcinoma (ESCC) in mice. Tumor xenograft models were established in the right forelimb of $20 \mathrm{BALB} / \mathrm{c}$ nude mice by subcutaneous injection. The tumor-bearing mice were randomly assigned to 4 treatment groups ( $n=5$ per group) as follows: the control group (saline), the ginsenoside $\mathrm{Rg} 3$ alone group $(6 \mathrm{mg} / \mathrm{kg} / \mathrm{day}$, once a day for 3 weeks), the chemotherapy alone group (paclitaxel $10 \mathrm{mg} / \mathrm{kg} /$ day + cisplatin $5 \mathrm{mg} / \mathrm{kg} /$ day on days $1,7,14$ and 21) and the chemotherapy $+\operatorname{Rg} 3$ group (combined treatment). The length and width of the tumor were directly measured with calipers at different time points and the tumor volume $\left(\mathrm{cm}^{3}\right)$ was calculated using the formula $0.52 \mathrm{x}$ length $\mathrm{x}$ width ${ }^{2}$ every other day. The mice were sacrificed by cervical dislocation following completion of therapy, the tumors were removed and weighed and the expression levels of $\mathrm{Ki}-67$ were determined by immunohistochemistry. The results indicated that the coadministration of ginsenoside $\operatorname{Rg} 3$ significantly enhanced the inhibitory effects of chemotherapy on tumor growth. In addition, the expression levels of Ki-67 in the chemotherapy + Rg3 group were significantly lower compared to those in the other 3 groups. The chemotherapy $+\operatorname{Rg} 3$ group also exhibited the lowest microvascular density among all four groups. These findings suggested that ginsenoside $\mathrm{Rg} 3$ may improve the antitumor efficacy of chemotherapy in Eca-109 ESCC in mice.
\end{abstract}

\section{Introduction}

Esophageal carcinoma is one of the most aggressive malignancies worldwide, with a poor prognosis and a mortality rate

Correspondence to: Dr Wei Liu, Department of Medical Oncology, The Fourth Hospital of Hebei Medical University, 12 Jiankang Road, Shijiazhuang, Hebei 050011, P.R. China

E-mail: changliang1081@163.com

*Contributed equally

Key words: ginsenoside Rg3, esophageal carcinoma, inhibition, chemotherapy approximating $100 / 10^{5}$ in China (1). The 2 subtypes of esophageal carcinoma, esophageal squamous cell carcinoma (ESCC) and esophageal adenocarcinoma (EAC), exhibit different incidences among different countries. EAC is currently rapidly increasing in incidence in the United States; however, ESCC remains the predominant histological type in Eastern countries, particularly China (2-4). Surgery remains the curative treatment option for patients with non-metastatic ESCC. However, $\geq 60 \%$ of the patients are unsuitable for surgery due to the advanced disease stage and the presence of comorbidities (5). Therefore, chemotherapy remains one of the main therapeutic options. Achieving an optimal therapeutic effect with chemotherapy is crucial in the treatment of esophageal cancer.

Ginsenoside $\mathrm{Rg} 3$, the active ingredient extracted from Panax ginseng, possesses anticancer properties and exerts various pharmacological effects $(6,7)$. Previous studies demonstrated that ginsenoside Rg3 may inhibit cancer growth in vitro and in vivo and is considered to be relatively safe (8-10). However, the molecular mechanisms underlying the effects of ginsenoside Rg3 have been not yet been fully elucidated. Ginsenoside Rg3 was reported to reduce tumor proliferation, angiogenesis and metastasis. Ginsenoside Rg3 may be a beneficial supplement, enhancing the inhibitory effects of chemotherapy.

This study used a ESCC xenograft mouse model to evaluate the tumor inhibitory effect of ginsenoside $\operatorname{Rg} 3$ combined with chemotherapy.

\section{Materials and methods}

Cell culture. Eca-109 human esophageal squamous carcinoma cells were purchased from the Cell Bank of the Chinese Academy of Sciences (Shanghai, China). The Eca-109 cells were cultured in RPMI-1640 medium (Gibco, Carlsbad, CA, USA) supplemented with $10 \%$ fetal bovine serum (Hangzhou Sijiqing Biological Engineering Materials Co., Ltd, Hangzhou, China) and $100 \mu \mathrm{g} / \mathrm{ml}$ streptomycin (NCPC, Shijiazhuang, China) and they were kept in an incubator containing $5 \% \mathrm{CO}_{2}$ at $37^{\circ} \mathrm{C}$.

Animals. Female BALB/c nude mice, weighing 18-20 g and aged 5-6 weeks, were purchased from Beijing HFK Bioscience Co., Ltd., (Beijing, China). All the mice were raised under specified 
Table I. Tumor volumes $\left(\mathrm{cm}^{3}\right)$ at different time points following treatment.

\begin{tabular}{lccccrr}
\hline & & \multicolumn{2}{c}{ Groups } & \\
\cline { 3 - 6 } Time points & No. & Control & Rg3 & TAX+DDP & TAX+DDP+Rg3 & P-value \\
\hline Day 0 & 5 & $0.136 \pm 0.008$ & $0.127 \pm 0.020$ & $0.147 \pm 0.018$ & $0.142 \pm 0.016$ & 0.2511 \\
Day 3 & 5 & $0.383 \pm 0.018$ & $0.406 \pm 0.015^{\mathrm{a}}$ & $0.291 \pm 0.018^{\mathrm{a}, \mathrm{b}}$ & $0.308 \pm 0.017^{\mathrm{a}, \mathrm{b}}$ & $<0.0001$ \\
Day 6 & 5 & $0.799 \pm 0.092$ & $0.863 \pm 0.076$ & $0.609 \pm 0.028^{\mathrm{a}, \mathrm{b}}$ & $0.648 \pm 0.149^{\mathrm{a}, \mathrm{b}}$ & 0.0019 \\
Day 9 & 5 & $1.067 \pm 0.083$ & $1.177 \pm 0.076$ & $0.882 \pm 0.107^{\mathrm{a}, \mathrm{b}}$ & $0.845 \pm 0.121^{\mathrm{a}, \mathrm{b}}$ & 0.0002 \\
Day 12 & 5 & $1.390 \pm 0.101$ & $1.416 \pm 0.100$ & $1.018 \pm 0.102^{\mathrm{a}, \mathrm{b}}$ & $0.959 \pm 0.126^{\mathrm{a}, \mathrm{b}}$ & $<0.0001$ \\
Day 15 & 5 & $1.597 \pm 0.101$ & $1.541 \pm 0.103$ & $1.050 \pm 0.113^{\mathrm{a}, \mathrm{b}}$ & $0.878 \pm 0.108^{\mathrm{a}, \mathrm{b}, \mathrm{c}}$ & $<0.0001$ \\
Day 18 & 5 & $1.890 \pm 0.137$ & $1.729 \pm 0.110^{\mathrm{a}}$ & $1.108 \pm 0.115^{\mathrm{a}, \mathrm{b}}$ & $0.774 \pm 0.102^{\mathrm{a}, \mathrm{b}, \mathrm{c}}$ & $<0.0001$ \\
Day 21 & 5 & $2.367 \pm 0.134$ & $1.931 \pm 0.107^{\mathrm{a}}$ & $1.165 \pm 0.123^{\mathrm{a}, \mathrm{b}}$ & $0.614 \pm 0.090^{\mathrm{a}, \mathrm{b}, \mathrm{c}}$ & $<0.0001$ \\
\hline
\end{tabular}

${ }^{\text {aP }}<0.05$ vs. control group at the same time point; ${ }^{\mathrm{b}} \mathrm{P}<0.05$ vs. $\mathrm{Rg} 3$ group at the same time point; ${ }^{\mathrm{c}} \mathrm{P}<0.05$ vs. TAX+DDP group at the same time point. TAX, paclitaxel; DDP, cisplatin.

pathogen-free conditions $\left(22 \pm 1^{\circ} \mathrm{C}, 12\right.$-h light/dark cycle) and fed with standard chow diet and tap water. The study experiments were performed in accordance with the guidelines approved by the Laboratory Animal Care Committee of Hebei Province.

Experimental design. The Eca-109 cells were diluted in phosphate-buffered saline to form a single-cell suspension. The right forelimbs of the BALB/c nude mice were subcutaneously injected with $5 \times 10^{6}$ cells $(0.1 \mathrm{ml}$ serum-free medium). When the diameter of tumors reached $7 \mathrm{~mm}$, the mice were randomly assigned to 4 treatment groups ( $n=5$ per group), namely the control group (saline treatment), the ginsenoside $\mathrm{Rg} 3$ alone, the chemotherapy alone and the chemotherapy + ginsenoside Rg3 groups. The mice in the control group were intraperitoneally injected with $0.2 \mathrm{ml} 0.9 \%$ saline for 21 days. The ginsenoside $\mathrm{Rg} 3$ group was treated with $0.2 \mathrm{ml}$ ginsenoside Rg3 (purity, 96.1\%; Zhejiang Yatai Pharmaceutical Co., Ltd., Shenzhen, Zhejiang, China) at $6 \mathrm{mg} / \mathrm{kg} /$ day by gavage administration once daily for 3 weeks. The chemotherapy group was administered a combination regimen (paclitaxel $10 \mathrm{mg} / \mathrm{kg} /$ day + cisplatin $5 \mathrm{mg} / \mathrm{kg} /$ day) intraperitoneally on days 1, 7, 14 and 21. Cisplatin was provided by World House Pharmaceuticals Co., Ltd., (Jiangsu, China) and paclitaxel was obtained from Ha Medicine Group (Harbin, China). The chemotherapy + ginsenoside Rg3 group received the same chemotherapy regimen combined with ginsenoside Rg3. Tumor size (length and width) was measured using calipers every other day and the tumor volumes $\left(\mathrm{cm}^{3}\right)$ were estimated using the formula $0.52 \mathrm{x}$ length $\mathrm{x}$ width $^{2}$. During the experimental period, the weight loss and any change in the drinking and/or eating habits of the mice was observed and recorded.

Immunohistochemistry and microvascular density (MVD) evaluation. After the xenograft mice were sacrificed by cervical dislocation, the tumor tissues were excised, weighed and fixed immediately in neutral formalin, then used for hematoxylin and eosin staining and immunohistochemical assays. Rabbit anti-human Ki-67 antibodies were used (dilution, 1:100; Zhongshan Golden Bridge Biotechnology Co., Ltd., Beijing, China). Ki-67 protein expression was detected with a SABC

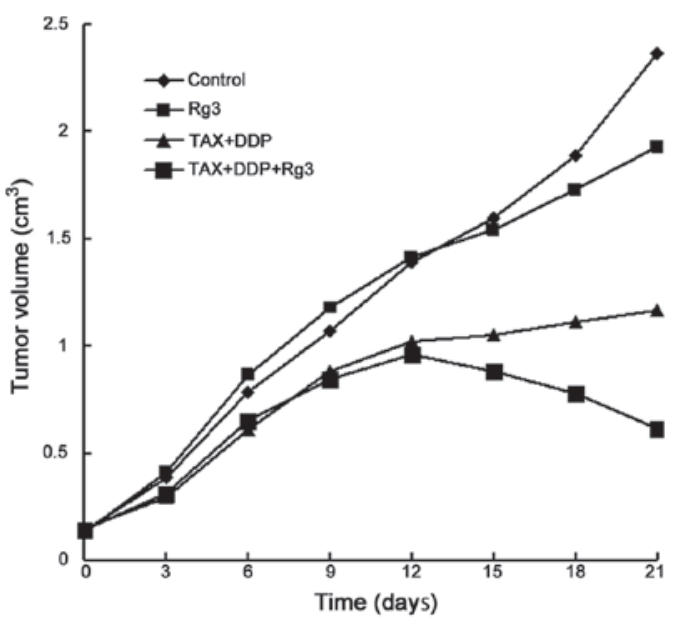

Figure 1. Ginsenoside $\operatorname{Rg} 3$ combined with chemotherapy significantly inhibited the growth of tumor xenograft in mice. The tumor volumes $\left(\mathrm{cm}^{3}\right)$ in different groups at different time points were measured. TAX, paclitaxel; DDP, cisplatin

kit according to the manufacturer's instructions (Booster Bioengineering Institute, Wuhan, China). To evaluate MVD, the sections were examined under a light microscope (BX41; Olympus, Tokyo, Japan) to identify 3 regions with the highest MVD. The microvessels were counted in these areas (magnification, x400) and the number of microvessels was recorded. The average number was defined as the MVD of the tumor.

Statistical analysis. The data are expressed as means \pm standard deviation. The Student's t-test and one-way analysis of variance were used to assess the statistical significance of the differences between treatment groups. Data analyses were performed with Statistical Analysis System V8 (SAS Institute Inc., Cary, NC, USA). $\mathrm{P}<0.05$ was considered to indicate a statistically significant difference.

\section{Results}

Animals. During the treatment period, no mice died in any of the groups until the experiment was completed. Furthermore, 
A

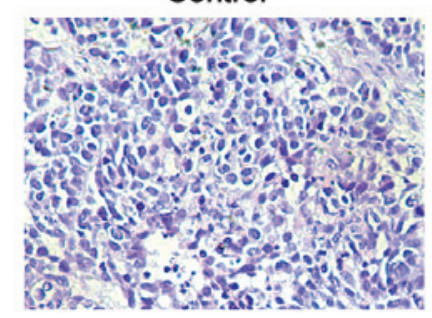

TAX+DDP

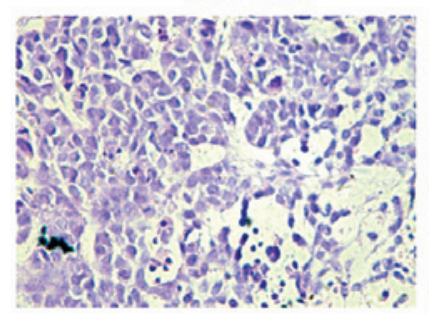

Rg3

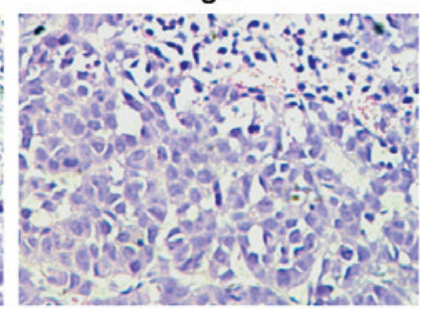

$T A X+D D P+R g 3$

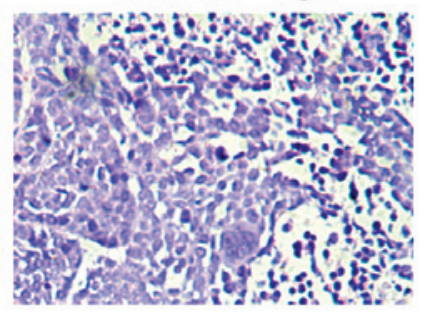

B

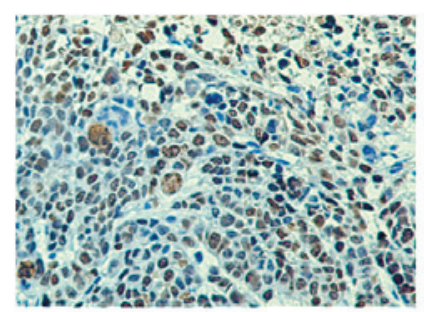

TAX+DDP

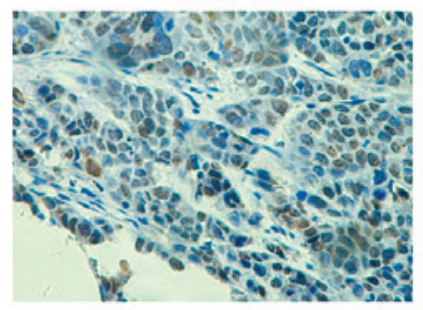

Rg3

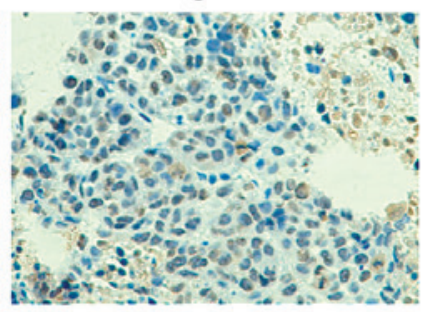

$T A X+D D P+R g 3$

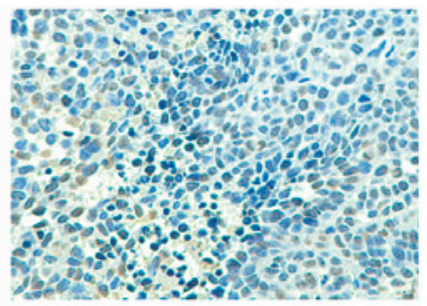

Figure 2. Histopathological and immunohistochemical assay of the tumor xenograft. (A) Hematoxylin and eosin staining. (B) The tumor cell proliferation was detected by Ki-67 staining (magnification, x200). TAX, paclitaxel; DDP, cisplatin.

Table II. Tumor weight and inhibitory rate of tumor in different groups.

\begin{tabular}{lccc}
\hline Groups & No. & Tumor weight $(\mathrm{g})$ & Inhibitory rate $(\%)$ \\
\hline Control & 5 & $1.847 \pm 0.111$ & - \\
Rg3 & 5 & $1.398 \pm 0.236^{\mathrm{a}}$ & 24.31 \\
TAX+DDP & 5 & $0.745 \pm 0.082^{\mathrm{a}}$ & 59.67 \\
TAX+DDP+Rg3 & 5 & $0.542 \pm 0.099^{\mathrm{a}}$ & 70.64 \\
\hline
\end{tabular}

${ }^{\mathrm{a}} \mathrm{P}<0.05$ vs. control group. TAX, paclitaxel; DDP, cisplatin.

the weight of the mice was not significantly reduced in any of the 4 groups and there were no significant treatment-related adverse effects.

Tumor size and inhibitory rate. The tumor volumes $\left(\mathrm{cm}^{3}\right)$ at different time points following treatment are shown in Table I. Prior to administration (day 0), the mean tumor volume did not differ significantly among the control, ginsenoside $\mathrm{Rg} 3$, chemotherapy and chemotherapy + ginsenoside Rg3 groups $\left(0.136 \pm 0.008,0.127 \pm 0.020,0.147 \pm 0.018\right.$ and $0.142 \pm 0.016 \mathrm{~cm}^{3}$, respectively; $\mathrm{P}=0.2511$ ). We observed that the tumor volume in the chemotherapy + ginsenoside $\mathrm{Rg} 3$ group at 15 days began to exhibit a significant decrease compared to the other 3 groups $(\mathrm{P}<0.0001)$. In the ginsenoside $\mathrm{Rg} 3$ group, the tumor volume was significantly lower compared to that in the control group at 18 days $(\mathrm{P}<0.0001)$, but higher compared to that in the chemotherapy alone and chemotherapy + ginsenoside Rg3 groups. As shown in Fig. 1, the growth curve of the tumor in different groups was drawn according to the mean tumor volumes. The inhibitory rates of the tumor in each group are listed in Table II. On day 21, the inhibitory rate of the tumor in the ginsenoside $\operatorname{Rg} 3$, chemotherapy and chemotherapy + ginsenoside $\operatorname{Rg} 3$ groups was $24.31,59.67$ and $70.64 \%$, respectively.

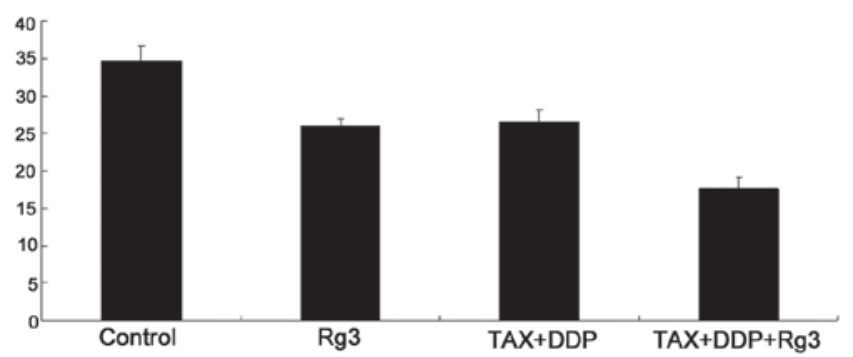

Figure 3. Microvascular density (MVD) of the tumor in each treatment group. The bars represent the average MVD. TAX, paclitaxel; DDP, cisplatin.

Staining characteristics. The tumor tissue specimens were stained with hematoxylin and eosin for the histopathological assay and the histopathological changes were examined under a light microscope. We observed that the chemotherapy + ginsenoside Rg3 group exhibited small, shadow-stained nuclei compared to the other groups (Fig. 2A). In addition, the staining for the proliferation marker Ki-67 in the chemotherapy + ginsenoside Rg3 group was less prominent compared to that in the other groups (Fig. 2B).

CD34 immunohistochemical staining was used to assess the microvasculature of the tumor. As shown in Fig. 3, the MVD was statistically significantly different among groups $(\mathrm{P}<0.05)$. The chemotherapy + ginsenoside $\mathrm{Rg} 3$ group exhibited the lowest MVD among the groups $(\mathrm{P}<0.05)$. These results demonstrated that the combination of ginsenoside $\mathrm{Rg} 3$ with chemotherapy exerted significant inhibitory effects on Eca-109 ESCC in mice.

\section{Discussion}

Ginseng has been a widely recognized traditional medicine in Eastern Asian countries for thousands of years and is becoming increasingly popular in Western countries. Accumulating studies suggest that the main anticancer ingredient of ginseng is ginsenoside $\operatorname{Rg} 3$ (11). A number of studies clearly demon- 
strated that ginsenoside $\operatorname{Rg} 3$ inhibits cancer growth in vivo and in vitro through reducing tumor proliferation, angiogenesis and metastasis (12-14).

Ginsenoside $\operatorname{Rg} 3$ combined with capecitabine enhanced antiangiogenic efficacy in breast cancer in mice and exhibited improved antitumor effects and reduced toxicity (15). In addition, ginsenoside Rg3 was shown to inhibit CXCR4 expression and related migrations in the MDA-MB-231 breast cancer cell line (16). $\operatorname{Rg} 3$ promoted the efficacy of cisplatin by inhibiting heme oxygenase 1 and NAD $(\mathrm{P}) \mathrm{H}$ dehydrogenase (quinone 1) expression in CT-26 colon cancer cells and protected the kidney and liver against tissue damage by preventing cisplatin-induced intracellular reactive oxygen species generation (17). In addition, ginsenoside $\operatorname{Rg} 3$ enhanced the susceptibility of SW620 and HCT116 colon cancer cells to docetaxel and other chemotherapeutic agents via nuclear factor $\kappa$-light-chain-enhancer of activated B cells $(\mathrm{NF}-\kappa \mathrm{B})$ inhibition (18). Jiang et al (19) reported that ginsenoside Rg3 inhibited hepatocellular carcinoma growth via the intrinsic apoptotic pathway. Moreover, ginsenoside Rg3 combined with gemcitabine was found to significantly inhibit angiogenesis and growth of lung cancer and improve survival and quality of life in tumor-bearing mice (20). Pan et al (21) reported that ginsenoside $\mathrm{Rg} 3$ attenuates cell migration via inhibition of aquaporin 1 expression in PC-3M prostate cancer cells. Furthermore, Kim et al (22) confirmed that the combination of ginsenoside $\mathrm{Rg} 3$ with docetaxel enhanced the susceptibility of prostate cancer cells via inhibition of $\mathrm{NF}-\kappa \mathrm{B}$. However, it had not been elucidated whether ginsenoside $\mathrm{Rg} 3$ combined with paclitaxel and cisplatin enhances their inhibitory effects on the Eca-109 xenograft in mice.

In our study, ginsenoside $\mathrm{Rg} 3$ in combination with chemotherapy significantly inhibited the growth of the Eca-109 xenograft in nude mice. After 3 weeks of treatment, the inhibitory rate in the ginsenoside $\mathrm{Rg} 3+$ chemotherapy group reached $70.64 \%$ and was significantly higher compared to that in the other treatment groups. In addition, the combination group exhibited a lower Ki-67 expression compared to that in the other 3 groups and the lowest MVD among all groups. In conclusion, ginsenoside $\mathrm{Rg} 3$ improved the antitumor efficacy of chemotherapy in Eca-109 ESCC in mice.

\section{References}

1. Liu M, Zhang F, Liu S, et al: Microsatellite analysis in multistage carcinogenesis of esophageal squamous cell carcinoma from Chongqing in Southern China. Int J Mol Sci 12: 7401-7409, 2011.

2. Berg D, Wolff C, Langer R, et al: Discovery of new molecular subtypes in oesophageal adenocarcinoma. PLoS One 6: e23985, 2011.

3. Liang Y, Hou X, Cui Q, et al: Skp2 expression unfavorably impacts survival in resectable esophageal squamous cell carcinoma. J Transl Med 10: 73, 2012.
4. Etemadi A, Abnet CC, Golozar A, et al: Modeling the risk of esophageal squamous cell carcinoma and squamous dysplasia in a high risk area in Iran. Arch Iran Med 15: 18-21, 2012.

5. Li R, Chen TW, Wang LY, et al: Quantitative measurement of contrast enhancement of esophageal squamous cell carcinoma on clinical MDCT. World J Radiol 4: 179-185, 2012.

6. Joo EJ, Ha YW, Shin H, et al: Generation and characterization of monoclonal antibody to ginsenoside rg3. Biol Pharm Bull 32: 548-552, 2009.

7. Shinkai K, Akedo H, Mukai M, et al: Inhibition of in vitro tumor cell invasion by ginsenoside Rg3. Jpn J Cancer Res 87: 357-362, 1996.

8. Luo X, Wang CZ, Chen J, et al: Characterization of gene expression regulated by American ginseng and ginsenoside $\mathrm{Rg} 3$ in human colorectal cancer cells. Int J Oncol 32: 975-983, 2008.

9. Kim K, Park M and Young Kim H: Ginsenoside Rg3 suppresses palmitate-induced apoptosis in MIN6N8 pancreatic beta-cells. J Clin Biochem Nutr 46: 30-35, 2010.

10. Lee SY, Kim GT, Roh SH, et al: Proteomic analysis of the anti-cancer effect of 20S-ginsenoside Rg3 in human colon cancer cell lines. Biosci Biotechnol Biochem 73: 811-816, 2009.

11. Dougherty U, Mustafi R, Wang Y, et al: American ginseng suppresses Western diet-promoted tumorigenesis in model of inflammation-associated colon cancer: role of EGFR. BMC Complement Altern Med 11: 111, 2011.

12. Wang CZ, Aung HH, Zhang B, et al: Chemopreventive effects of heat-processed Panax quinquefolius root on human breast cancer cells. Anticancer Res 28: 2545-2551, 2008.

13. Zhang C, Liu L, Yu Y, et al: Antitumor effects of ginsenoside Rg3 on human hepatocellular carcinoma cells. Mol Med Rep 5: 1295-1298, 2012.

14. Yuan HD, Quan HY, Zhang Y, et al: 20(S)-Ginsenoside $\mathrm{Rg} 3$-induced apoptosis in HT-29 colon cancer cells is associated with AMPK signaling pathway. Mol Med Rep 3: 825-831, 2010.

15. Zhang Q, Kang X, Yang B, et al: Antiangiogenic effect of capecitabine combined with ginsenoside $\mathrm{Rg} 3$ on breast cancer in mice. Cancer Biother Radiopharm 23: 647-653, 2008.

16. Chen XP, Qian LL, Jiang H and Chen JH: Ginsenoside Rg3 inhibits CXCR4 expression and related migrations in a breast cancer cell line. Int J Clin Oncol 16: 519-523, 2011.

17. Lee CK, Park KK, Chung AS and Chung WY: Ginsenoside $\operatorname{Rg} 3$ enhances the chemosensitivity of tumors to cisplatin by reducing the basal level of nuclear factor erythroid 2-related factor 2-mediated heme oxygenase-1/NAD $(\mathrm{P}) \mathrm{H}$ quinone oxidoreductase- 1 and prevents normal tissue damage by scavenging cisplatin-induced intracellular reactive oxygen species. Food Chem Toxicol 50: 2565-2574, 2012.

18. Kim SM, Lee SY, Yuk DY, et al: Inhibition of NF-kappaB by ginsenoside Rg3 enhances the susceptibility of colon cancer cells to docetaxel. Arch Pharm Res 32: 755-765, 2009.

19. Jiang JW, Chen XM, Chen XH and Zheng SS: Ginsenoside Rg3 inhibit hepatocellular carcinoma growth via intrinsic apoptotic pathway. World J Gastroenterol 17: 3605-3613, 2011.

20. Liu TG, Huang Y, Cui DD, et al: Inhibitory effect of ginsenoside $\mathrm{Rg} 3$ combined with gemcitabine on angiogenesis and growth of lung cancer in mice. BMC Cancer 9: 250, 2009.

21. Pan XY, Guo H, Han J, et al: Ginsenoside Rg3 attenuates cell migration via inhibition of aquaporin 1 expression in PC-3M prostate cancer cells. Eur J Pharmacol 683: 27-34, 2012.

22. Kim SM, Lee SY, Cho JS, et al: Combination of ginsenoside Rg3 with docetaxel enhances the susceptibility of prostate cancer cells via inhibition of NF-kappaB. Eur J Pharmacol 631: 1-9, 2010 . 